\title{
Three-Dimensional Microstructural Characterization of Cast Iron Alloys for Numerical Analyses
}

\author{
Kent Salomonsson ${ }^{1, a *}$ and Anders E. W. Jarfors ${ }^{2, b}$ \\ ${ }^{1}$ Department of Product Development, School of Engineering, Jönköping University, Box 1026, \\ SE-551 11 Jönköping, Sweden \\ ${ }^{2}$ Department of Materials and Manufacturing, School of Engineering, Jönköping University, Box \\ 1026, SE-551 11 Jönköping, Sweden \\ akent.salomonsson@ju.se, banders.jarfors@ju.se
}

Keywords: Cast iron, microstructure, characterization, X-ray, tomography

\begin{abstract}
In this paper, we aim at characterizing three different cast iron alloys and their microstructural features, namely lamellar, compacted and nodular graphite iron. The characterization of microscopic features is essential for the development of methods to optimize the behavior of cast iron alloys; e.g. maximize thermal dissipation and/or maximize ductility while maintaining strength. The variation of these properties is commonly analyzed by metallography on two-dimensional representations of the alloy. However, more precise estimates of the morphologies and material characteristics are obtained by three-dimensional reconstruction of microstructures. The use of X-ray microtomography provides an excellent tool to generate high resolution threedimensional microstructure images. The characteristics of the graphite constituent in the microstructure, including the size, shape and connectivity, were analyzed for the different cast iron alloys. It was observed that the lamellar and compacted graphite iron alloys have relatively large connected graphite morphologies, as opposed to ductile iron where the graphite is present as nodules. The results of the characterization for the different alloys were ultimately used to generate finite element models.
\end{abstract}

\section{Introduction}

In the beginning, cast iron was only known as white or gray. The invention of the microscope in 1860 opened up for an improved understanding of the microstructure of cast iron. Ductile iron, also known as nodular iron, was independently invented by Adey, Millis and Morrogh just before 1940. During the 1970s, compacted graphite iron was developed and the major effect of the alloying elements magnesium and cerium was understood [1]. Later studies also clarified the influence of oxygen, where decreasing oxygen content in the melt caused transformation from flake graphite to compacted and eventually to spheroidal shape graphite [2].

In most cases the graphite is part of a eutectic reaction following the primary growth of austenite, and for example for ductile iron, the eutectic reaction is highly divorced. Due to the nature of the phase transformations occurring post solidification, the study of the complete sequence of solidification is difficult. Direct austempering is necessary to reveal the primary austenite, but this will affect solid-state transformation effect on the precipitation of graphite [3][4].

When casting compacted and ductile iron, deviation from the intended graphite shape is common and ductile iron is defined as a material with more than $80 \%$ spherical nodules. Compacted graphite is defined as a material with less than $20 \%$ spherical nodules. The exact nature of the growth of graphite is still under debate following Herfurth [5] who suggested that the transition from lamellar to spheroidal graphite was due to the change of ratio of the growth rate of the

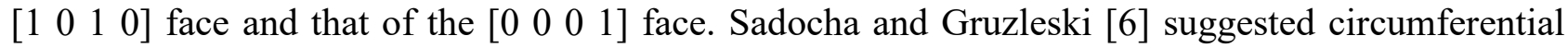
growth of graphite spheroids, while later studies propose growth which is more in the shape of platelets stacked together [7]. The fact that the different morphologies can occur simultaneously in the microstructure makes it difficult to interpret the precipitation sequence in the eutectic through 
standard cross-sectioning as shape and distribution of the different morphologies cannot be visualized in a two dimensional cross-section.

The development of methods to describe the local microstructural features of different cast iron alloys has been the focus of many studies in literature $[8,9,10,11]$. Most of these studies are intended to quantify for example volume fractions of different constituents, nodularity, mean curvatures etc. All of these properties will aid in determining what type of grade the supposed buyer will obtain from the supplier. Velischko et al. [8] developed an analytical method to determine the grade of cast iron. The method is based on training an algorithm to recognize the graphite morphology by image analysis. By use of a database of binary images that covers known grades of cast iron alloys which have been thoroughly analyzed by experts in the field, the algorithm can search for similarities and thus determine the grade. This approach limits the determination to 2D binary images. With the large spectrum of graphite morphologies observed in two dimensions, it is obviously interesting to capture and analyze the microstructure in three dimensions. The Focused Ion Beam (FIB) method has therefore been applied in recent years. The method "deep-etches" the cast iron specimen by basically slicing it to generate a free surface. The free surface is analyzed by scanning electron microscopy (SEM) to generate 2D images which are collected and the resulting stack of images is analyzed by a software to generate the $3 \mathrm{D}$ microstructure [9]. The method is mainly used to analyze small variations in the microstructure. It is, however, cumbersome to study larger volumes by this technique. Volumes are generally smaller than $1 \mathrm{~mm}^{3}$. It is thus apparent that the resolution obtained by FIB is probably the best available today to generate 3D microstructures of cast iron alloys. Another promising method to study $3 \mathrm{D}$ microstructures is $\mathrm{X}$-ray microtomography or $\mu-\mathrm{CT}$. With this method it is possible to establish the morphology and volume fraction of different phases, i.e. ferrite, pearlite and graphite [12].

In the present work, we aim to study the 3D microstructures of Spherical Graphite Iron (SGI), Compacted Graphite Iron (CGI) and Lamellar Graphite Iron (LGI) with the use of $\mu-\mathrm{CT}$ combined with images analysis, ultimately generating Finite Element Models of the microstructures.

\section{X-Ray Microtomography}

X-ray tomograms were collected using a Nikon XT H 225 CT scanner, employing a W reflection target with power settings for the source of $135 \mathrm{kV}$ acceleration voltage and $110 \mathrm{~mA}$ filament current, respectively. The samples were machined as cylindrical rods with diameter $1 \mathrm{~mm}$, allowing them to be placed at a minimum distance from the source such that the upper nominal resolution limit of about $1 \mu \mathrm{m}$ voxel size could be obtained.

For the cast iron samples, the main purpose of the tomography analysis was to characterize the different constituents in terms of distributions, sizes and morphologies, and accordingly the sample dimensions and the experimental settings had to be optimized to achieve maximum spatial resolution with a sample volume large enough to be statistically representative for the phases of interest. Figure 1 shows slices reconstructed from the tomograms of three different cast iron alloys.
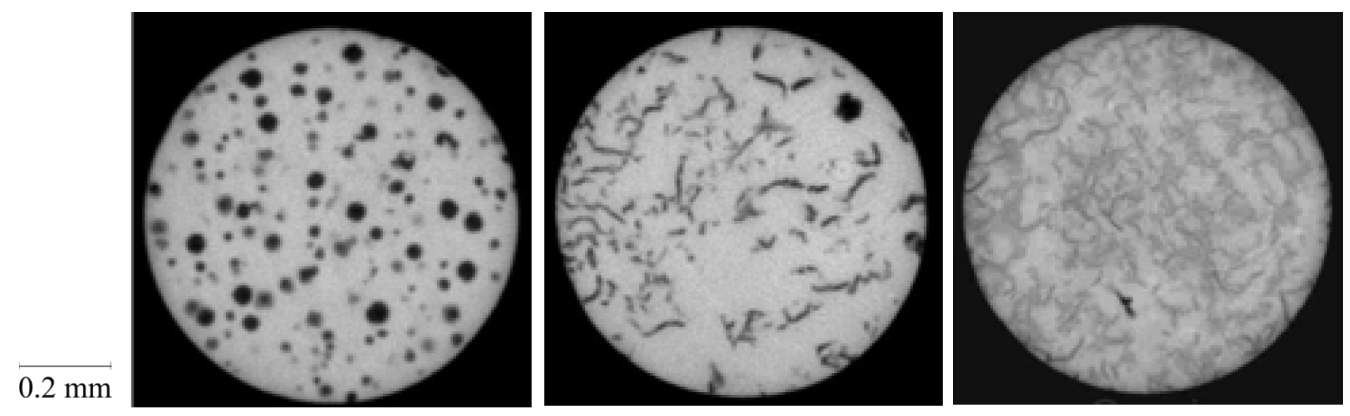

Figure 1. Example of radiographs for SGI (left), CGI (middle) and LGI (right).

As can be observed in Figure 1, it is quite difficult to differentiate the phases. Thus, it is recommended that an image analysis is done prior to any segmentation in order to distinguish between different phases in the microstructure. Figure 2 shows an example of how for example 
probability density analysis can be used to analyze individual radiographs for a SGI microstructure. For comparison, the original radiograph is also shown. Obviously, there is a multitude of image analysis techniques available, however, here we merely point out, as mentioned above, that it is most often necessary to perform an image analysis before any segmentation of phases begin. Note that the ferrite phase surrounding the graphite becomes visible in the processed image, see Figure 2.

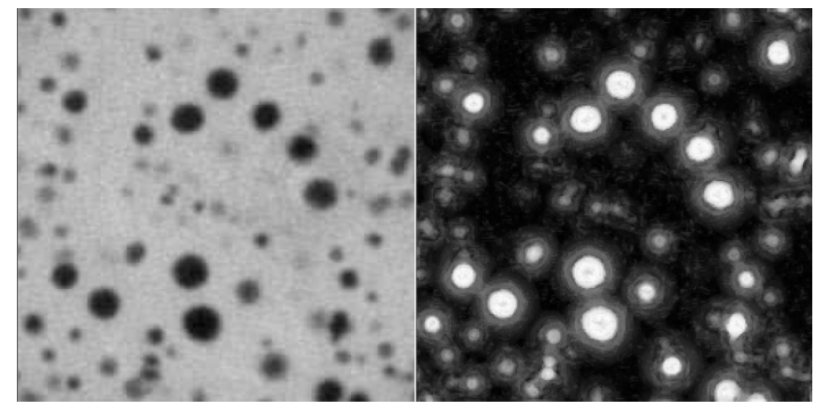

Figure 2. Example of a SGI microstructure radiograph (left), probability density of intensity (right).

The bit depth of the radiographs is also a factor to consider since, for the case of 8-bit pictures, the image intensity is limited to values between 0-255, whereas for the 16-bit depth images it lies between 0-4095. Thus, details in intensity shift can be captured more easily for the 16-bit images.

\section{Microstructures}

Once the images have been pre-analyzed using image analysis software, each image is segmented to establish the extent of each microstructural phase. Interpolation of the segmented images was performed to yield three-dimensional representations of the microstructures, see e.g. [13] for a fairly recent study on three-dimensional analysis using $\mu-\mathrm{CT}$.

Depending on the complexity of the microstructural features, the generated stereolithographic representations, i.e. STL-format files, will typically have differently sized facets. However, in finite element applications it is favorable to have the same size for all finite elements and specifically for dynamic simulations. Thus, extensive pre-processing is necessary in order to generate finite element models.

\subsection{Spherical graphite iron}

Known for its excellent castability, high strength and ductility, SGI is used in many applications in industry. The microstructure is characterized by spherical nodules of graphite, where a particular alloy will for example have a specific so-called nodularity that can roughly range between $65-85 \%$ depending on the shape factor used. Figure 1 (left) shows a typical pearlitic-ferritic SGI radiograph. Obviously, the nodules will appear to be of different size due to the particular cut. Thus, from 2D radiographs it is tricky to estimate the size distribution of nodules. However, analysis of a $\mu-\mathrm{CT}$ scan reveals the actual size of individual nodules and it is thus straight forward to establish size distributions. Another characteristic feature that is interesting to analyze is the nearest neighbor distance between nodules. This has been shown in literature to be directly linked to the strength of the particular SGI alloy. Again, this is a feature that can be determined in 3D analyses rather than 2D approximations. Some of these features will be presented in the result section of the current manuscript.

\subsection{Compacted graphite iron}

Owing to the development of foundry and manufacturing technology in the late 1990's, CGI has been used in series production of primarily diesel engine components, such as cylinder heads, for about 20 years. The primary benefits of CGI compared to grey iron, i.e. LGI, or aluminum is its higher strength and fatigue resistance properties. These properties are important due to the increasing demand for lighter vehicles in order to reduce fuel consumption while maintaining or even increasing power of the engines [14]. 
The microstructure is characterized by a certain amount of nodularity, about $10-20 \%$ and its vermicular shaped graphite inclusions (see Figure 1 (middle)) while the matrix is preferably pearlitic.

3.3. Lamellar graphite iron

One of the disadvantages of LGI has been covered briefly above, and it is its lower strength as compared to SGI and CGI. However, due to inexpensive production and excellent heat conducting properties and vibration damping ability, LGI is used frequently in industry. Moreover, LGI is used for contact sliding condition components such as for example piston rings [15]. The graphite flake morphology is observed to be self-lubricating under certain sliding conditions.

The nodularity for LGI is $0 \%$ and the graphite inclusions are in form of large graphite flakes or lamellas, which is the reason for the naming convention in literature, i.e. flake graphite iron (FGI), lamellar graphite iron (LGI) or grey iron.

\section{Results and Discussion}

Structural properties of cast irons are determined by their microstructure. It is therefore essential to be able to correctly characterize microstructural features. For example, characteristics such as nodule size, nodularity and volume all have to do with ultimate tensile strength properties. For SGI, which is also referred to as ductile iron, the microstructure is characterized by spherical inclusions in a matrix that is constituted by pearlite and ferrite as well as fully ferritic ductile iron. When the microstructure is loaded, the graphite inclusions act similar to voids and stress concentrations build up in the graphite/matrix interfaces. Consequently, if graphite inclusions are modelled as voids, the external work will dissipate in terms of plastic dissipation and fracture energy of the matrix phase and not the graphite. The apparent difference in strength between the SGI, CGI and LGI is due to graphite morphology. The relatively small round graphite inclusions in SGI compared to vermicular shaped inclusions, with some fraction of spherical nodules for CGI, and the flake graphite in LGI behaves differently under loading conditions. Relatively large graphite inclusions will deform under loading and the majority of the external work energy will, thus, dissipate in terms of fracture energy of the graphite as well and as a result lead to lower strength and ductility. The focus of the present study is to characterize graphite morphologies for SGI, CGI, LGI and relate it to results obtained from finite element simulations.

Figure 3 shows a frequency plot of the nodule size for the SGI microstructure, originating from the X-ray tomography. For clarity, the nodules were idealized as perfect spheres. It is seen that it is most common with nodules having a surface area of about $0.0025 \mathrm{~mm}^{2}$ and that there is a number of nodules that have a larger area. 


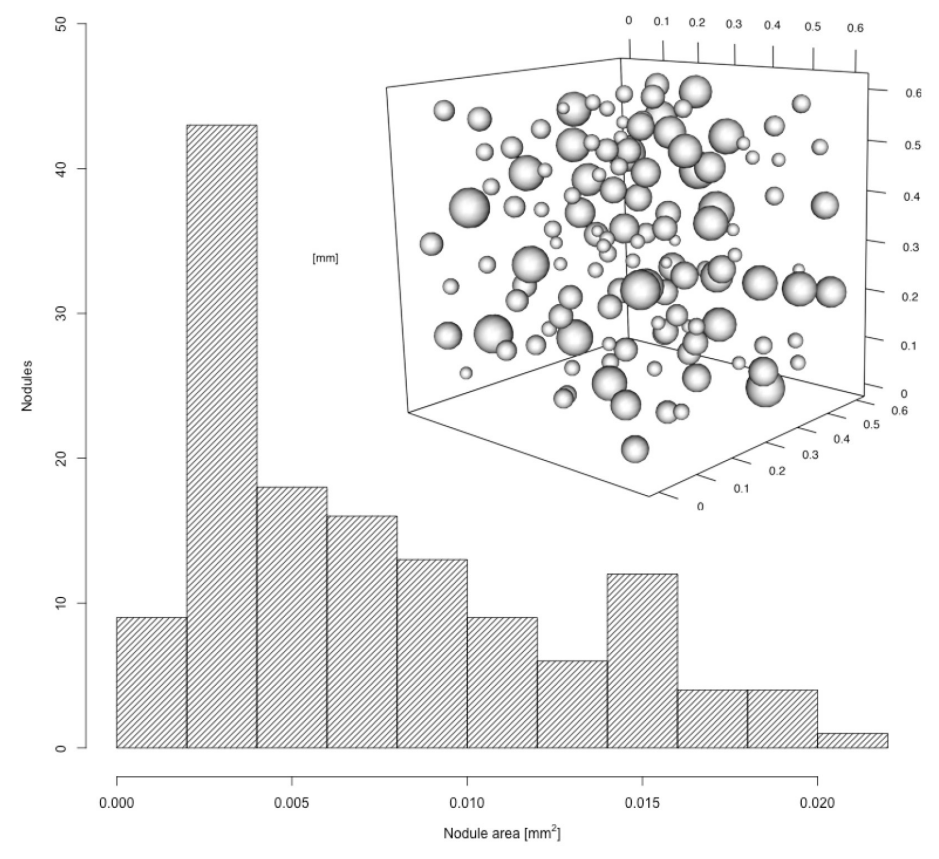

Figure 3. Distribution of nodule sizes for the SGI microstructure.

In the present study, the representative volume elements (RVE) are about $0.7 \times 0.7 \times 0.7 \mathrm{~mm}^{3}$ and as is seen in Figure 3, there is a slight increase of nodules having a surface area of about $0.015 \mathrm{~mm}^{2}$ which corresponds to a nodule diameter of about $35 \mu \mathrm{m}$. Thus, defining $35 \mu \mathrm{m}$ as a large spherical inclusion (e.g. nodule 51), the following dendrogram, see Figure 4 (left), can be constructed. Smaller nodules than this have been left out, see Figure 4 (right). It shows that there are three cluster formations in the current representative volume for the SGI with a couple of outliers as well, namely nodules 3,4 and 135 and the distance between nodules in the clusters is approximately $100 \mu \mathrm{m}$.
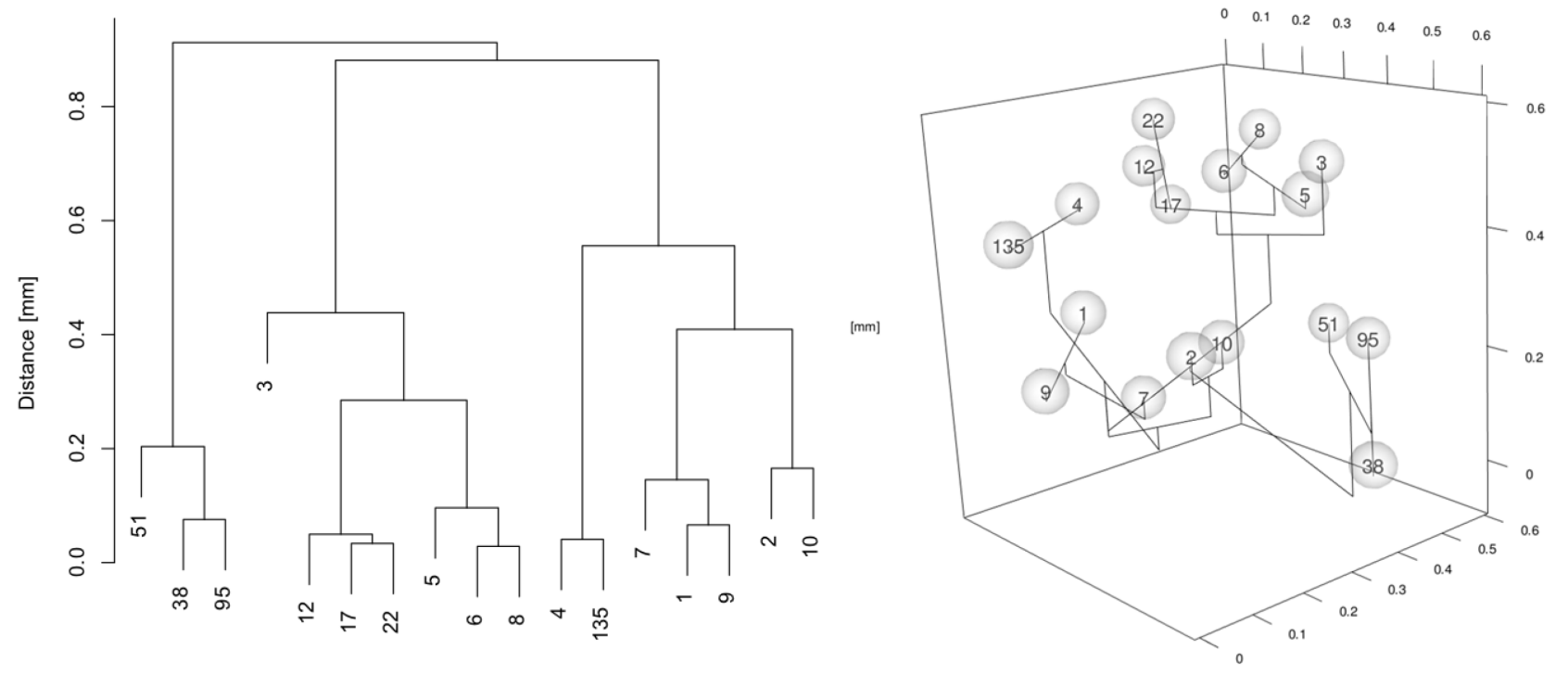

Figure 4. Dendrogram (left) showing the distance between nodules (for the SGI microstructure) that have a larger surface area than $0.015 \mathrm{~mm}^{2}$. The locations of the nodules is shown for clarity in the right plot.

The localization of strain for the SGI graphite clusters is similar to the effect larger graphite inclusions have on the CGI and the LGI microstructures analyzed, namely, that the graphite has a ductile effect and essentially allows the microstructure to deform.

In fact, knowledge about the number of inclusions, the total surface area and the volume fraction yields enough information to draw conclusions about the shape of the graphite inclusions. Table 1 
shows this data for the analyzed microstructures. The larger volume fraction of graphite for the SGI and the smaller surface area suggest that the individual shapes must be voluminous, whereas for the CGI and LGI microstructures, the area is larger, but the volume fraction is lower. This suggests that the graphite inclusions must be less voluminous, i.e. vermicular or flakes.

To illustrate this conclusion, Figure 5 shows a histogram of the number of CGI graphite inclusions as function of the surface area. Like for the SGI, the graphite inclusions have here been idealized as spheres by calculating the radius from the individual surface areas. It is apparent that the graphite inclusions need to be less voluminous in order to uphold the volume fraction criteria.

Table 1. Surface area and volume fraction for the studied cast iron alloys.

\begin{tabular}{|c|c|c|}
\hline $\begin{array}{c}\text { Alloys } \\
\text { (inclusions) }\end{array}$ & $\begin{array}{c}\text { Surface Area Graphite } \\
{\left[\mathrm{mm}^{2}\right]}\end{array}$ & $\begin{array}{c}\text { Volume fraction graphite } \\
{[-]}\end{array}$ \\
\hline $\begin{array}{c}\text { SGI } \\
(135)\end{array}$ & 0.973 & 0.269 \\
\hline $\begin{array}{c}\text { CGI } \\
(233)\end{array}$ & 2.195 & 0.146 \\
\hline $\begin{array}{c}\text { LGI } \\
(81)\end{array}$ & 3.863 & 0.144 \\
\hline
\end{tabular}

The distance between the inclusions is also roughly the same for all inclusions as shown in the dendrogram in Figure 6. It should be noted that out of the approximately 230 graphite inclusions for the CGI microstructure, only the ones that have a surface area exceeding $0.015 \mathrm{~mm}^{2}$ are shown in Figure 6. The nodularity for CGI microstructures varies between $0-20 \%$ and the analyzed CGI RVE contains spherical nodules as can be seen in Figure 5 (right).
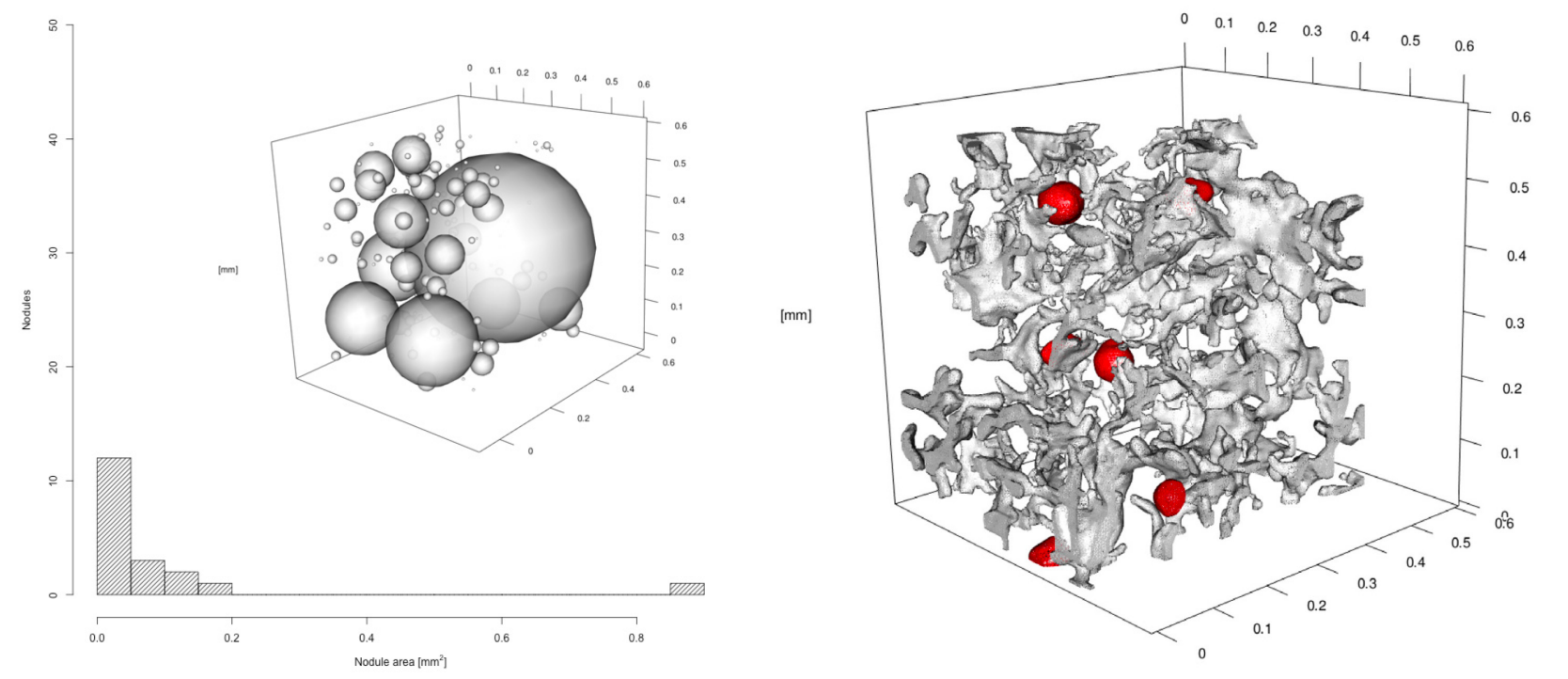

Figure 5. Distribution of graphite inclusions for the CGI microstructure (left). For simplicity, the graph only shows graphite inclusions larger than $0.015 \mathrm{~mm}^{2}$. Actual graphite morphology for the CGI, where the spherical inclusions are shown in red (right). 


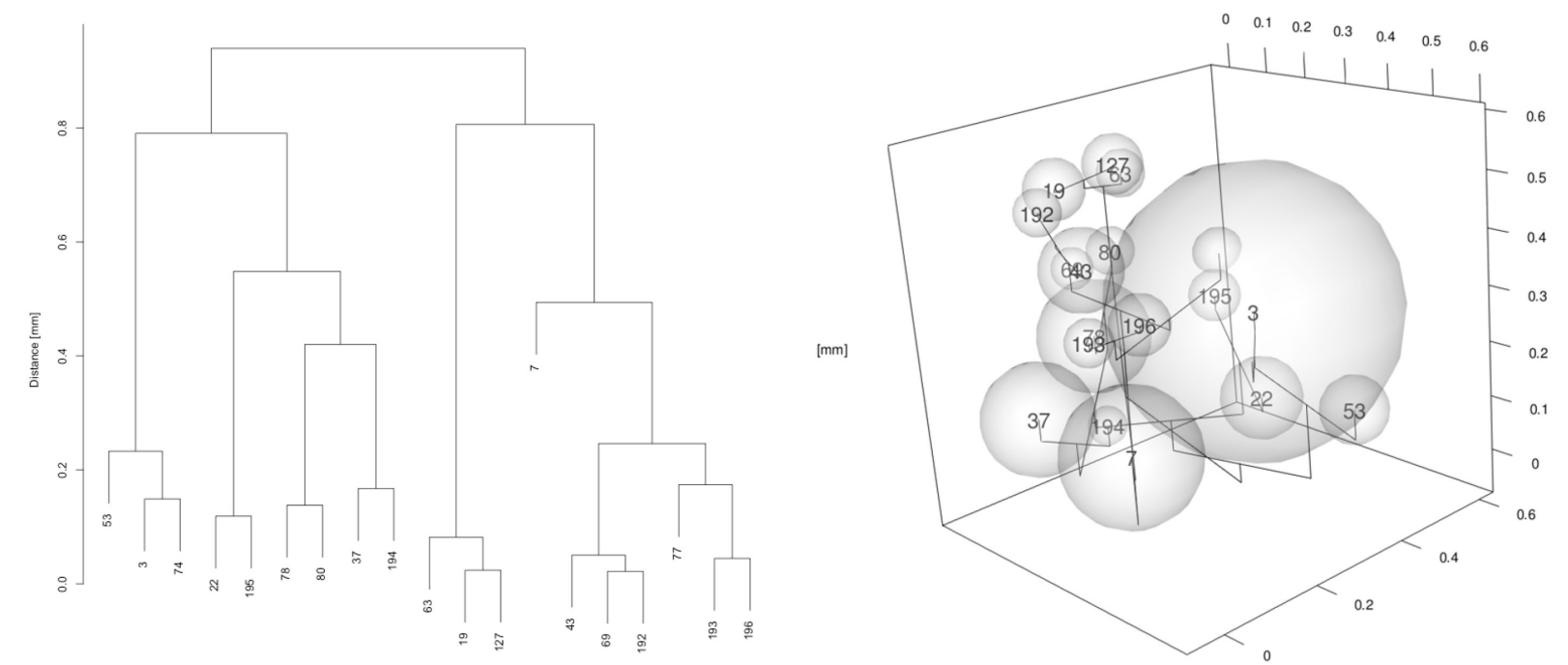

Figure 6. Dendrogram (left) showing the distance between graphite inclusions for the CGI microstructure that have a larger surface area than $0.015 \mathrm{~mm}^{2}$. The locations of the inclusions are shown for clarity in the right plot.

Similar to the CGI microstructure, the LGI microstructure has large interconnected flake-like graphite inclusions, but $0 \%$ nodularity. Nevertheless, for the purpose of comparison, the inclusions are idealized as spheres in the same manner as before. For the present LGI microstructure, there are approximately 80 inclusions in total. The number of inclusions larger than $0.015 \mathrm{~mm}^{2}$ are fewer than 20, where the biggest interconnected inclusion has a surface area of $2.827 \mathrm{~mm}^{2}$, see Figure 7 .

Here, the largest inclusion is an outlier with a fairly large distance to the surrounding inclusions. In fact, since the RVE is cut from the specimen scan, the surface area of the largest inclusion is actually larger.

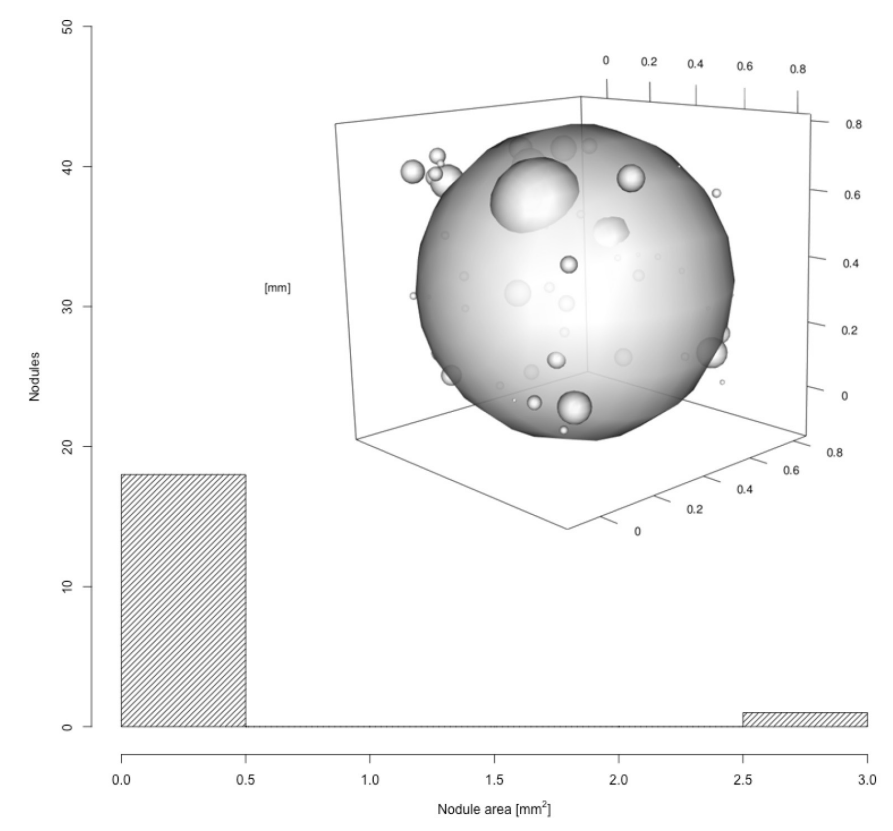

Figure 7. Distribution of graphite inclusions for the LGI microstructure. For simplicity, the graph only shows graphite inclusions larger than $0.015 \mathrm{~mm}^{2}$.

Relating the cluster formations observed in the SGI microstructure to the evolution of plastic strain and for a specific load case, it is observed that the clusters localize the plastic strain, see Figure 8. This effect is not as prominent for the other two microstructures due to the aforementioned homogenized ductility given by the larger graphite inclusions as can be seen in the two lower contour plots in Figure 8. 

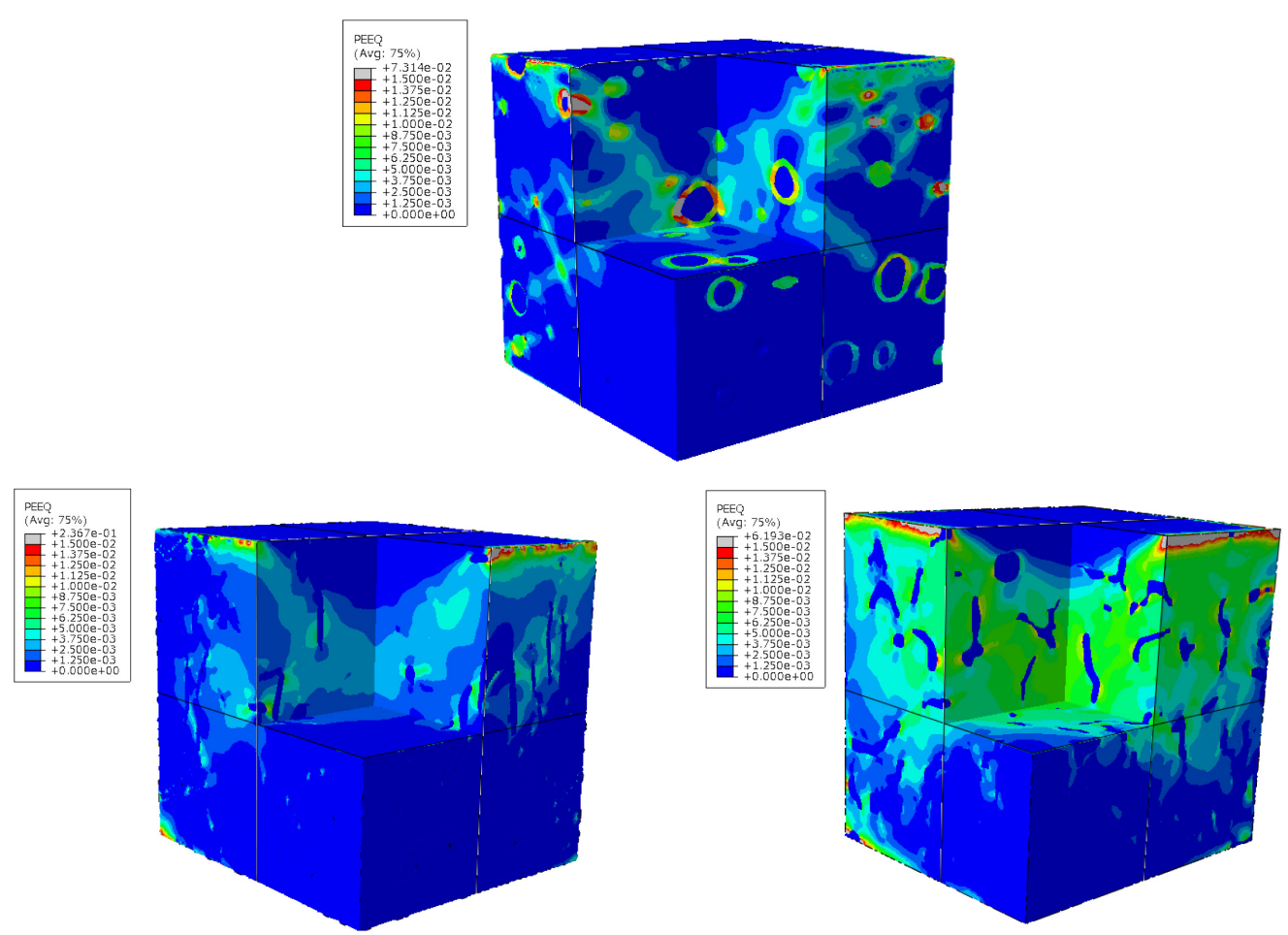

Figure 8. Contour plots of effective plastic strain for the SGI (top), CGI (lower left) and LGI (lower right) microstructures.

\section{Conclusions}

Three different cast iron microstructures have been characterized based on the graphite morphology alone. It has been shown that total surface area and volume fraction of the graphite unambiguously correlates with the suspected shape of individual graphite inclusions. Furthermore, the use of dendrograms provide an excellent method for the analysis of cluster formation in particular for SGI microstructures due to the spheroidal nature of the graphite inclusions. As a final conclusion, the use of $\mu-\mathrm{CT}$ to analyze cast iron microstructures has been proven to be an outstanding approach to generate finite element models that can be used in several studies to come.

\section{Acknowledgements}

The authors would like to acknowledge the Swedish knowledge foundation for financial support of the CompCAST research profile at Jönköping University. The authors would also like to thank Professor Ragnvald Mathiesen and Professor Arne Dahle for valuable contribution regarding the manuscript.

\section{References}

[1] D.M. Stefanescu, Solidification and modeling of cast iron-A short history of the defining moments. Mat Sci Eng A - Struct 413-414(2005), 322-333.

[2] E. Nechtelberger, H. Puhr, J.B. von Nesselrode, A. Nakayasu, Proceedings of the 49th International Foundry Congress, CIATF, Chicago, 1982, Paper 1.

[3] G. Rivera, P.R. Calvillo, R. Boeri, Y. Houbert, J. Sikora, Examination of the solidification macrostructure of spheroidal and flake graphite cast irons using DAAS and ESBD. Mater Charact, 59 (2008), 1342-1348.

[4] A. Diószegi, K.Z. Liu, I.L. Svensson, Inoculation of primary austenite in grey cast iron. Int J Cast Metal Res, 20 (2) (2007), 68-72.

[5] K. Herfurth, Freiberger Forschungsh. [Freiburg Research Journals], Dept. B, No. 105 (1966), 267-310. 
[6] J.P. Sadocha, J.E. Gruzleski, in: B. Lux, I. Minkoff, F. Mollard (Eds.), The Metallurgy of Cast Iron, Georgi Publjishing Co., St. Saphorin,Switzerland, 1974, p. 443

[7] K. Theuwissen, M. Lafont, L. Laffont, B. Viguier, J. Lacaze, Microstructural characterization of graphite spheroids in ductile iron. T Indian I Metals 65 (6) (2012), 627-631.

[8] A. Velichko, C. Holzapfel, A. Siefers, K. Schladitz K and F. Mücklich, Unambiguous classification of complex microstructures by their three-dimensional parameters applied to graphite in cast iron Acta Mater. 56 (2008), 1981-90.

[9] A. Hatton A, M. Engstler, P. Leibenguth and F. Mücklich, Characterization of graphite crystal structure and growth mechanisms using FIB and 3D image analysis Adv. Eng. Mater. 13 (2011), 136-144.

[10] B.I. Imasogie and U. Wendt, Characterization of graphite particle shape in spheroidal graphite iron using a computer-based image analyzer J. Min. Mater. Char. Eng. 3 (2004), 1-12

[11] H. Toda, I. Sinclair, J. Y. Buffiére, E. Maire, K. H. Khor, P. Gregson and T. Kobayashi, A 3D measurement procedure for internal local crack driving forces via synchrotron X-ray microtomography Acta Mater. 52 (2004), 1305-17.

[12] G. Fischer, J. Nellesen, N. B. Anar, K. Ehrig, H. Riesemeier and W. Tillmann, 3D analysis of micro-deformation in VHCF-loaded nodular cast iron by mCT. Mat Sci Eng A - Struct 577 (2013), 202-209.

[13] D. Seo, F. Tomizato, H. Toda, K. Uesugi, A. Takeuchi, Y. Suzuki and M. Kobayashi, Spatial resolution of synchrotron X-ray microtomography in high energy range: Effect of X-ray energy and sample-to-detector distance. Appl. Phys. Lett., 101 (2012), 1-5.

[14] M. König, M. Wessén, Influence of alloying elements on microstructure and mechanical properties of CGI. Int J Cast Metal Res, 23 (2) (2010), 97-110.

[15] R. Ghasemi, L. Elmquist, The relationship between flake graphite orientation, smearing effect, and closing tendency under abrasive wear conditions, Wear, 317 (2014), 153-162. 